Gerontology 1984;30:144

\title{
International Association of Gerontology
}

\section{Sandoz Prize for Gerontological Research}

The prize will be worth 20,000 Swiss Francs, and will be sponsored by Sandoz Ltd, Basel (Switzerland), with the purpose of encouraging research in all areas of gerontology and geriatric medicine including biological, medical, psychological, social and other relevant aspects with special emphasis on multidisciplinary research programs.

The Jury consists of the Executive Committee of the IAG. The prize will be awarded on the occasion of the 13th International Congress of Gerontology, New York, N.Y., 12-17 July, 1985. Applications in English should comprise a summary of the research work of 3-5 pages, curriculum vitae, bibliography and reprints of not more than 3 pivotal publications in English or with extended summaries in English.

Individuals, research teams or institutions are invited to submit their applications in English not later than 15 September 1984 to Prof. M. Bergener, MD, Secretary General, International Association of Gerontology, Rheinische Landesklinik, Wilhelm-Griesin-ger-Strasse 23, D-5000 Cologne 91, FRG. 